\title{
Is low FODMAP diet effective in children with irritable bowel syndrome?
}

\author{
(iD) Guzide Dogan, ${ }^{1}$ (D) Sibel Yavuz, ${ }^{1}$ (D) Hale Aslantas, ${ }^{2}$ (D) Beyhan Cengiz Ozyurt, ${ }^{3}$ (D) Erhun Kasirga ${ }^{1}$ \\ ${ }^{1}$ Department of Pediatric Gastroenterology, Hepatology and Nutrition, Celal Bayar University Faculty of Medicine, Manisa, Turkey \\ ${ }^{2}$ Department of Nutrition and Dietetics, Celal Bayar University Faculty of Medicine, Manisa, Turkey \\ ${ }^{3}$ Department of Public Health, Celal Bayar University Faculty of Medicine Manisa, Turkey
}

\begin{abstract}
OBJECTIVE: There is growing evidence that suggests that consumption of fermentable oligosaccharides, disaccharides, monosaccharides and polyols (FODMAPs) may result in some symptoms in certain patients with irritable bowel syndrome (IBS). This study aims to evaluate the efficacy of a low FODMAP diet in children with IBS by comparing it with the standard diet.

METHODS: Sixty children between the ages of 6 and 18 who were diagnosed with IBS according to Rome IV criteria were included in this study. Randomly selected patients were divided into two groups as 30 patients on a low FODMAP diet and 30 patients on a general protective standard diet for the gastrointestinal tract. Patients were evaluated at the beginning, second and fourth months of the study. The data of the patients were recorded in the demographic data form. Patients were asked to score abdominal pain using the Visual Analogue Scale (VAS). The clinical status of the patient was scored by the doctor using the Clinical Global Impression Improvement (CGI-I) scale.

RESULTS: There were no significant differences between groups about age, sex and symptom duration. When the pre-diet VAS scores were compared, the two groups were similar. The mean decrease in VAS score after two months of diet was $3.80 \pm 1.10$ in the low FODMAP group and $2.03 \pm 1.03$ in the standard group and was statistically significant. Post-dietary CGI-I score evaluation was determined to be statistically significant between the two groups. The increase in VAS scores in the fourth month was $2.97 \pm 1.10$ points in the Low FODMAP group and $1.63 \pm 0.71$ in the standard group, and was statistically significant. CGI-I score after the diet at the $4^{\text {th }}$ month was also statistically significant between the two groups.
\end{abstract}

CONCLUSION: A low FODMAP diet seems to be more effective for symptom control in IBS when compared to standard dietary advice. Further studies are needed for the unknowns that will be used in clinical practice, such as how long the diet will be continued and how effective it will be in which GIS diseases.

Keywords: Functional gastrointestinal disorders; irritable bowel syndrome; low FODMAP diet.

Cite this article as: Dogan G, Yavuz S, Aslantas H, Cengiz Ozyurt B, Kasirga E. Is low FODMAP diet effective in children with irritable bowel syndrome? North Clin Istanb 2020;7(5):433-437.

Cunctional gastrointestinal disorders (FGID) are a - group of diseases in children are characterized by chronic and recurrent complaints of the upper or lower gastrointestinal system, where there are no structural or biochemical abnormalities, the symptoms cannot be explained by another medical condition after proper evaluation, and the underlying pathophysiological mechanisms are not well known $[1,2]$. Abnormal gastrointestinal motility, visceral hypersensitivity, changes in brain intestinal interactions, psychosocial factors and gastrointestinal microbiota have been reported to be effective in the pathophysiology of FGID [3-5]. 
According to Rome 4 criteria, FGID in children and adolescents was classified as functional nausea and vomiting, functional abdominal pain disorders, and functional defecation disorders. Subtypes of functional abdominal pain disorders include irritable bowel syndrome (IBS), functional dyspepsia, abdominal migraine, and otherwise unspecified abdominal pain [6]. The removal of lactose, fructose, caffeine, spicy and fatty foods, carbonated drinks and gas-forming vegetables from the diet that triggers symptoms in FGID may be beneficial in some patients [7]. The fermentable oligo-di-monosaccharide and polyols (FODMAPs) are difficult to absorb, fermentable carbohydrates, with high osmotic charges. They increase water secretion and fermentation in small intestine and colon, resulting in short-chain fatty acid and gas formation $[8,9]$. Adult studies have shown the efficacy of a low FODMAP diet in FGID $[10,11]$. The studies on children are limited [12].

The present study aims to evaluate the efficacy of a low FODMAP diet in children with irritable bowel syndrome by comparing it with the standard diet.

\section{MATERIALS AND METHODS}

Sixty children between the ages of six and 18, who presented at the pediatric gastroenterology clinic of our university and who were diagnosed with IBS according to Rome IV criteria and who accepted to participate in this study, were included in the present study. Patients diagnosed with IBS at a similar age and gender were randomized using haphazard sampling, and patients were assigned to the groups. The study protocol was approved by the local ethics committee $(28.09 .2016$; 20478486 327 ) and written informed consent was obtained from a parent or legal guardian. Sample size was calculated with power analysis. When $\alpha=0.05$ was taken, a minimum of 30 patients were calculated for every group with the power of $85 \%$ and effect size $(d)=0.70$.

Patients with alarm symptoms indicating organic disease, such as bloody diarrhea, abdominal pain which awakens them from sleep, fever, joint disorders, weight loss, organomegaly on physical examination, signs of perianal disease, malnutrition, and patients younger than six years of age, were excluded from this study.

Patients who accepted to participate in this study were evaluated at the beginning, second and fourth months of this study. The data of the patients were recorded in the demographic data form. Abdominal pain, abdominal distention, defecation habits were questioned. Patients were asked to score abdominal pain using the Visual Analogue Scale (VAS). VAS is usually $10 \mathrm{~cm}$ long, horizontal or vertical line, starting with "No Pain" and ending with "Unbearable Pain". According to VAS, pain severity is generally rated as 0 points for "no pain" and 10 points for "worst pain imaginable". It is generally accepted that the vertical line is easier to understand. Patients over the age of five have described this method as easy to understand and easy to apply [13].

At the first examination, the patients were referred to the dietitian for nutrition regulation. Nutritional lists were prepared by the dietitian to provide protein, calorie, vitamin and mineral intake appropriate to the age of the patients and nutrition training was provided. Randomly selected patients were divided into two groups as 30 patients on a low FODMAP diet, and 30 patients on a standard gastrointestinal tract protective diet.

Patients on a low FODMAP diet were scheduled to be fed with a FODMAP of less than $0.5 \mathrm{~g}$ per meal. The patients were given a list of prohibited and allowed foods in their diet and recipes were suggested to increase their compliance with the diet. The control group was provided with a healthy diet list that would avoid chocolate, caffeine, acidic, spicy foods and high-fat foods in order to provide age-appropriate protein, calorie, vitamin and mineral intake. Patients who were called for control in the second month of dietary treatment were asked to score their pain with VAS. The clinical status of the patient was scored by their doctor using the Clinical Global Impression Improvement (CGI-I) scale [14]. CGI-I scale was used to score symptoms, such as abdominal pain, boalting and general well-being status of the patient. The CGI-I is a 7-point scale that is designed to measure overall improvement from the baseline status. This measure has been used in several clinical trials [15]. Scores range from 1 (very much improved) through 4 (no change) to 7 (very much worse). The scores of "much improved" or "very much improved" were used to define a positive response; all other scores indicated a negative response.

At the end of the second month, dietary treatments were discontinued. The patients were called for follow-up two months after the discontinuation of diet therapy. In the $4^{\text {th }}$ month, patients were asked to score their pain again with VAS. In the $4^{\text {th }}$ month, the CGI-I scale was evaluated and scored by the attending physician.

Data were evaluated using descriptive statistics (number, percentage distribution, mean, median, standard 
TABLE 1. Demographic data of the patients

\begin{tabular}{|c|c|c|}
\hline & $\begin{array}{c}\text { Low FODMAP } \\
\text { group } \\
(n=30)\end{array}$ & $\begin{array}{c}\text { Standard } \\
\text { group } \\
(n=30)\end{array}$ \\
\hline Age $($ Mean $\pm S D) *$ & $13.40 \pm 2.60$ & $13.46 \pm 2.75$ \\
\hline Sex M/F** & $20 / 10$ & $18 / 12$ \\
\hline \multicolumn{3}{|c|}{ Symptom duration, month } \\
\hline $\begin{array}{l}(\text { Mean } \pm \text { SD })^{*} \\
\text { Abdominal distension }\end{array}$ & $9.66 \pm 6.64$ & $13.16 \pm 9.55$ \\
\hline Yes/no, n** & $26 / 4$ & $25 / 5$ \\
\hline Pre-diet VAS scores* & $6.7 \pm 0.77$ & $6.53 \pm 1.14$ \\
\hline
\end{tabular}

FODMAP: Fermentable oligosaccharides, disaccharides, monosaccharides and polyols; SD: Standard deviation; VAS: Visual analogue scale; *: T-test; **: Chi-square test.

deviation, min-max values), independent groups t-test (student's t-test) and chi-square test.

\section{RESULTS}

In this study, 60 patients were studied: 30 in the low FODMAP group and 30 in the standard group. Demographics of the study population are detailed in Table 1 . There were no significant differences between groups regarding age, sex and symptom duration. When the pre-dietary VAS scores were compared, the two groups were similar. The mean VAS score of the Low FODMAP group was $6.97 \pm 0.77$, and for the standard group, it was $6.53 \pm 1.14$. There was no statistical significance ( $p>0.05)$. Abdominal bloating was found to be $86.6 \%$ in the low FODMAP group, and $83.3 \%$ in the standard group.

After two months of the diet, the decrease in the VAS score of the two groups was evaluated. The mean decrease in the VAS score was $3.80 \pm 1.10$ in the low FODMAP group, whereas it was $2.03 \pm 1.03$ in the stan- dard group and this was found to be statistically significant $(p=0.0001)$ (Table 2). When CGI-I scores at two months were evaluated, it was seen that $13(43.3 \%)$ patients were much improved in the low FODMAP group and only one $(3.3 \%)$ patient was much improved in the standard group. In the standard group, the highest rate of no change was seen in 19 (63.3\%) patients. In Table 3 , CGI-I scores of the patients in the $2^{\text {nd }}$ month are detailed. Post-dietary CGI-I score was statistically significant between the two groups $(\mathrm{p}=0.0001)$.

Increased VAS scores were evaluated two months after (at the fourth month) the discontinuation of diet therapy. The increase in the low FODMAP group was $2.97 \pm 1.10$ points, whereas the increase in the standard group was $1.63 \pm 0.71$ and this was statistically significant $(p=0.0001)$. Table 2 shows the mean VAS score of the groups and their changes with the diet. When the CGI-I scores at the $4^{\text {th }}$ month were evaluated, 20 $(66.7 \%)$ patients were found to be minimally worse in the low FODMAP group, while 15 (50.0\%) patients were minimally worse in the standard group. In the 4-month post-dietary assessment, no change was observed in 14 $(46.7 \%)$ patients in the standard group after cessation of the diet $(p=0.0007)$. In Table 3, the CGI-I scores of the patients at four months were detailed.

\section{DISCUSSION}

Functional gastrointestinal disorders and IBS are a significant group of diseases that may affect individuals' quality of life when symptoms do not diminish despite various treatments. Nutritional habits are thought to trigger symptoms, but can also reduce symptoms when beware of diet [16]. Lately, and simultaneously with the increase in the prevalence of FGID, the Western dietary pattern has changed, with an increased intake of fructose and fructans due to increased consumption of processed and wheat-based foods and polyols, in response to the

TABLE 2. VAS score changes evaluated based on abdominal pain symptom at two months of diet and at four months, after the cessation of diet

\begin{tabular}{lrr} 
& Low FODMAP & \multicolumn{1}{c}{$\begin{array}{c}\text { Standard } \\
\text { group }(\mathrm{n}=30)\end{array}$} \\
\hline Average decrease in VAS score after two months of diet $(n=30)$ & $3.80 \pm 1.10$ & $2.03 \pm 1.03$ \\
Average increase in VAS score two months after cessation of diet & $2.97 \pm 1.10$ & $\mathbf{0 . 0 0 0 1}$ \\
\hline
\end{tabular}

VAS: Visual analogue scale; FODMAP: Fermentable oligosaccharides, disaccharides, monosaccharides and polyols. 
TABLE 3. CGI-I scores after diet and two months after cessation

Low FODMAP group

$(n=30) \%$
Standard group

$(n=30) \%$ p

\begin{tabular}{|c|c|c|}
\hline \multicolumn{3}{|l|}{$2^{\text {nd }}$-month CGI-I scores } \\
\hline $1=$ very much improved & 23.3 & 3.3 \\
\hline $2=$ much improved & 43.3 & 3.3 \\
\hline $3=$ minimally improved & 20 & 30 \\
\hline $4=$ no change & 13.3 & 63.3 \\
\hline \multicolumn{3}{|l|}{$4^{\text {th }}$-month CGI-I scores } \\
\hline $4=$ no change & 3.3 & 46 \\
\hline $5=$ minimally worse & 66.7 & 50.0 \\
\hline $6=$ much worse & 30.0 & \\
\hline
\end{tabular}

$2^{\text {nd }}$-month CGI-I scores

$1=$ very much improved
3.3

3.3

46.7

3.3
0.0001

0.0007

CGI-I: The Clinical Global Impression Improvement; FODMAP: Fermentable oligosaccharides, disaccharides, monosaccharides and polyols.

increased demand for sugar-free products [9]. This increased intake of FODMAPs may promote the onset of abdominal pain in children with IBS because these substances are poorly absorbed by the small intestine and are fermented by colonic bacteria, this generates gases and subsequently abdominal distension. Due to this, it can be said that having a low-FODMAP diet would decrease carbohydrate fermentation, osmotic activity and gas formation in the intestinal system, therefore preventing abdominal distension and pain in these children.

In recent years, the effectiveness of the low FODMAP diet as one of the dietary treatments of IBS has been investigated. A large number of studies have been published investigating the efficacy of a low FODMAP diet when compared to a traditional diet in releasing IBS symptoms in adults, but there are have not been many conducted studies in the pediatric population. In this study, for the pediatric population, the low FODMAP diet was found to be effective in children with IBS.

In adults studies, it has been reported that symptoms, such as abdominal pain, bloating, diarrhea and constipation, are reduced with a low FODMAP diet of six or eight weeks $[7,17]$. Different studies in IBS patients have shown that a low FODMAP diet reduces symptoms $[8,18]$.

The first study on children was conducted as a small open-label pilot study in Texas, United States. Low FODMAP diet was found to be effective in reducing abdominal pain compared to the baseline, which is the usual diet of the child [19].
In a study conducted with children aged 7-17, a decrease in symptoms was found in patients receiving a low FODMAP diet [18], and another study found that low FODMAP was effective in reducing IBS symptoms [8]. In our study, after the diet, the VAS scores of the low FODMAP group were significantly lower than the standard diet group. The improvement in the low FODMAP group after two months of diet was significantly higher than that of the standard diet group. To our knowledge, our study is the first study in the literature to evaluate IBS using VAS and CGI-I scores together. These scales were used separately for different diseases in the literature. In our study, we think that the use of these two scales together strengthens our data. Data on the duration of the low FODMAP diet in the literature are also limited. We limited our diet to two months because we thought there might be a problem in our patients' compliance with the diet. Continuing the diet for longer may reduce compliance and may also lead to nutritional deficiencies.

The data of our study were similar to the meta-analysis, which shows that a low-FODMAP diet improves the symptoms of IBS patients and abdominal pain and bloating symptoms of our patients regressed [11]. In a review evaluating the effectiveness of low FODMAP diet on growth and physiological development due to it being a restrictive diet in children, it was stated that low FODMAP was effective in chronic functional abdominal pain. However, there was no clear interpretation as to how long this diet should continue. To our knowledge, since there is no study on the nutritional effects of the 
low FODMAP diet in the literature, diet therapy was terminated in two weeks [12]. In our study, although the compliance of the patients with dietary treatment was complete within two months, we had patients who stated that they could not continue the low FODMAP diet even though their complaints regressed at two months. This suggests that a low FODMAP diet for children lasting more than two months will make it difficult for them to comply with the diet.

\section{Conclusion}

The low-FODMAP diet is effective when it comes to the management of abdominal symptoms in children who are diagnosed with IBS. There is a need for comprehensive studies to investigate unknowns related to the implementation of the low FODMAP diet in clinical practice, such as how long the diet should be, how effective it is in which gastrointestinal system disease, the long-term effects on the nutritional status, and the impacts on overall human health.

Ethics Committee Approval: The study protocol was approved by the local ethics committee (28.09.2016; 20478486-327).

Informed Consent: Written informed consent was obtained from a parent or legal guardian.

Conflict of Interest: No conflict of interest was declared by the authors.

Financial Disclosure: The authors declared that this study has received no financial support.

Authorship Contributions: Concept - GD, SY, EK; Design - GD, SY; Supervision - GD, BCO, EK; Materials - GD, SY, HA; Data collection and/or processing - GD, SY, HA; Analysis and/or interpretation - GD, BCO; Literature review - GD, HA, EK; Writing - GD, SY; Critical review - GD, EK.

\section{REFERENCES}

1. Rasquin A, Di Lorenzo C, Forbes D, Guiraldes E, Hyams JS, Staiano A, et al. Childhood functional gastrointestinal disorders: child/adolescent. Gastroenterology 2006;130:1527-37. [CrossRef]

2. Hyman PE, Milla PJ, Benninga MA, Davidson GP, Fleisher DF, Taminiau J. Childhood functional gastrointestinal disorders: neonate/ toddler. Gastroenterology 2006;130:1519-26. [CrossRef]

3. Mayer EA, Tillisch K. The brain-gut axis in abdominal pain syndromes. Annu Rev Med 2011;62:381-96. [CrossRef]

4. Levy RL, Olden KW, Naliboff BD, Bradley LA, Francisconi C, Drossman DA, et al. Psychosocial aspects of the functional gastrointestinal disorders. Gastroenterology 2006;130:1447-58. [CrossRef]
5. Simrén M, Barbara G, Flint HJ, Spiegel BM, Spiller RC, Vanner $\mathrm{S}$, Verdu EF, et al; Rome Foundation Committee. Intestinal microbiota in functional bowel disorders: a Rome foundation report. Gut 2013;62:159-76. [CrossRef]

6. Hyams JS, Lorenzo CD, Saps M, Shulman RJ, Staiano A, Tilburg MV. Childhood Functional Gastrointestinal Disorders: Child/Adolescent. Gastroenterology 2016;150:1456-68. [CrossRef]

7. Staudacher HM, Whelan K, Irving PM, Lomer MC. Comparison of symptom response following advice for a diet low in fermentable carbohydrates (FODMAPs) versus standard dietary advice in patients with irritable bowel syndrome. J Hum Nutr Diet 2011;24:487-95. [CrossRef]

8. Böhn L, Störsrud S, Liljebo T, Collin L, Lindfors P, Törnblom H, et al. Diet low in FODMAPs reduces symptoms of irritable bowel syndrome as well as traditional dietary advice: a randomized controlled trial. Gastroenterology 2015;149:1399-407. [CrossRef]

9. Baranguán Castro ML, Ros Arnal I, García Romero R, Rodríguez Martínez G, Ubalde Sainz E. Implementationof a low FODMAP dietforfunctional abdominal pain. An Pediatr (Barc) 2019;90:180-6.

10. Maagaard L, Ankersen DV, Végh Z, Burisch J, Jensen L, Pedersen N, et al. Follow-up of patients with functional bowel symptoms treated with a low FODMAP diet. World J Gastroenterol 2016;22:4009-19.

11. Altobelli E, Del Negro V, Angeletti PM, Latella G. Low-FODMAP Diet Improves Irritable Bowel Syndrome Symptoms: A Meta-Analysis. Nutrients 2017;9:940. [CrossRef]

12. Fodor I, Man SC, Dumitrascu DL. Low fermentable oligosaccharides, disaccharides, monosaccharides, and polyols diet in children. World J Clin Cases 2019;7:2666-74. [CrossRef]

13. Hawker GA, Mian S, Kendzerska T, French M. Measures of adult pain: Visual Analog Scale for Pain (VAS Pain), Numeric Rating Scale for Pain (NRS Pain), McGill Pain Questionnaire (MPQ), Short-Form McGill Pain Questionnaire (SF-MPQ), Chronic Pain Grade Scale (CPGS), Short Form-36 Bodily Pain Scale (SF-36 BPS), and Measure of Intermittent and Constant Osteoarthritis Pain (ICOAP). Arthritis Care Res (Hoboken) 2011;63 Suppl 11:S240-52. [CrossRef]

14. Spearing MK, Post RM, Leverich GS, Brandt D, Nolen W. Modification of the Clinical Global Impressions (CGI) Scale for use in bipolar illness (BP): the CGI-BP. Psychiatry Res 1997;73:159-71. [CrossRef]

15. Shafti SS. Aripiprazole Versus Lithium in Management of Acute Mania: a Randomized Clinical Trial. East Asian Arch Psychiatry 2018;28:80-4.

16. Celebi F, Akbulut G. Current Dietary Approaches in Bowel Diseases: Low Fermentable Oligo-, Di- and Mono-Saccharides and Polyols (FODMAP) Diet: Review. Türkiye Klinikleri J Gastroenterohepatol 2014;21:43-52. [CrossRef]

17. Ong DK, Mitchell SB, Barrett JS, Shepherd SJ, Irving PM, Biesiekierski JR, et al. Manipulation of dietary short chain carbohydrates alters the pattern of gas production and genesis of symptoms in irritable bowel syndrome. J Gastroenterol Hepatol 2010;25:1366-73. [CrossRef]

18. Halmos EP, Power VA, Shepherd SJ, Gibson PR, Muir JG. A diet low in FODMAPs reduces symptoms of irritable bowel syndrome. Gastroenterology 2014;146:67-75. [CrossRef]

19. Chumpitazi BP, Hollister EB, Oezguen N, Tsai CM, McMeans AR, Luna RA, et al. Gut microbiota influences low fermentable substrate diet efficacy in children with irritable bowel syndrome. Gut Microbes 2014;5:165-75. [CrossRef] 